\title{
A Hegemonia Americana no Pós-Guerra Fria: Continuidade ou Declínio? ${ }^{1}$
}

The American Hegemony in the Post-Cold War: Continuity or Decline?

Deijenane Gomes dos Santos ${ }^{2}$

\section{RESUMO}

O presente trabalho analisou as ideias sobre a longevidade e o possível declínio dos EUA como império no pós-Guerra Fria. A partir desta análise, foi possível entender que, apesar de grandes reveses sofridos pelos EUA tanto no campo econômico, quanto estratégico militar, um possível declínio total do império americano não se apresenta como uma realidade iminente.

Palavras-chave: EUA; império; declínio.

\begin{abstract}
This study analyzed the ideas about the longevity and the possible decline of the US as an empire in the post -Cold War context. From this analysis, it was possible to understand that, besides the some setbacks experienced by the US both economically and militarily the total decline of the American empire doesn't present itself as an imminent reality.
\end{abstract}

Key-words: US; empire; decline

\section{Hegemonia americana no pós-Guerra Fria}

Com o fim da Guerra Fria, entrava em cena um mundo moldado por uma única potência hegemônica, os EUA. Este novo momento nas Relações Internacionais seria marcado pela forte presença militar americana e por redefinições estratégicas no que concerne à dominação de regiões importantes do globo, como o Oriente Médio e a Ásia.

A economia americana também era um pilar do poderio dos EUA logo após o fim da Guerra Fria. Nos anos Clinton, por exemplo, houve um crescimento histórico e os americanos desfrutavam das benesses promovidas por uma economia aparentemente

\footnotetext{
${ }^{1}$ Artigo recebido em 28 de agosto de 2013 e aprovado para publicação em 10 de outubro de 2013.

2 Mestranda em Ciência Política, UFPE, Recife, Brasil.
} 
vibrante, além de levantarem a bandeira do mercado livre aos quatro cantos do mundo. Mas este crescimento foi contraditório, uma vez que no pós-Guerra Fria, os EUA se tornaram o grande devedor mundial e só poderiam ser vistos como bem-sucedidos economicamente, de fato, na esfera financeira, haja vista a dominação americana neste campo, exemplificada pelo poder do dólar nas transações econômicas pelo mundo, e pela dominância de Wall Street no sistema financeiro mundial (MANN, 2006). Além dos aspectos militar e econômico, há ainda o chamado soft power, termo cunhado por Joseph Nye, que juntos formam a tríade que sustenta os EUA como potência hegemônica desde o fim da Guerra Fria até os dias que correm (KEOHANE; KATZENSTEIN, 2005). Com exceção dos fiascos diplomáticos das guerras civis na Bósnia (1992) e na Somália (1993), do genocídio em Ruanda (1994) e do escândalo sexual do presidente Clinton, os EUA passaram pela década de 1990 praticamente incólumes do ponto de vista de uma possível ameaça ao seu prestígio como o grande xerife do mundo.

\section{0 conceito de hegemonia}

A posição hegemônica dos EUA, termo aplicado aqui segundo a definição feita por autores como Kindleberger, Amin e Fiori, tem sido controversa no meio acadêmico. Para Gramsci, hegemonia seria a dominação que alguns grupos exerciam sobre outros agrupamentos por meio da construção de um consenso político-ideológico, que incorporaria tanto os grupos dominantes quanto os dominados. Gramsci afirma que os grupos subordinados não se submeteriam por fraqueza ou ignorância, mas porque teriam motivos para acreditar que a liderança exercida por outro grupo seria de alguma maneira benéfica. Assim, a liderança, ou a própria hegemonia, não seria praticada apenas por meios coercitivos, mas de forma cultural e ideológica também.

Trazendo este pensamento para o contexto das relações interestatais, poder-se-ia dizer que os EUA exerceriam sua hegemonia sobre o sistema mundial por meio da imposição, algumas vezes de maneira não pacífica, de sua dominação. Charles Kindleberger (1973) formula uma tese que descreve a necessidade que o sistema mundial tem de ter a liderança de uma nação que funcione como estabilizadora (hegemon), a qual deve fornecer condições para o bom funcionamento das relações entre os países por meio de uma moeda forte, da defesa do livre comércio, uma coordenação de políticas 
econômicas e a garantia do sistema financeiro. A partir desta ideia, presente na Teoria da Estabilidade Hegemônica, Immanuel Wallerstein e Giovanni Arrighi também definirão não apenas a condição dos EUA como única potência hegemônica, mas também vão enfatizar que o momento dos EUA como o único hegemon está próximo do fim, haja vista o declínio de sua liderança no cenário internacional, o que para tais autores seria um indício do fim de um ciclo (Arrighi) ou do próprio sistema interestatal que se conhece hoje (Wallerstein).

Na visão de Samir Amin (2004), os EUA podem ser classificados como o único hegemon, segundo o termo usado pioneiramente por Kindleberger, uma vez que nenhuma outra nação faz frente aos americanos, ao menos, no quesito militarismo. 0 autor afirma que os EUA exercem sua função de xerife do mundo, ainda que para isso, tenha recorrido, em muitos casos, a ações arbitrárias, como as incursões militares no Oriente Médio. Fiori (2008) segue a mesma linha de raciocínio dos autores mencionados no que se refere à definição do termo hegemonia, quando a apresenta como a capacidade dos EUA de ser superior às outras nações do globo nas áreas econômica e militar. 0 uso do termo hegemonia neste artigo foi feito segundo as definições apresentadas pelos autores mencionados, em outras palavras, entende-se hegemonia como a capacidade que uma nação tem de impor sua liderança e dominação às outras por meio de recursos militares, econômicos e até culturais.

Segundo Fiori (2008), autores como Wallerstein e Arrighi compartilham a visão de que a hegemonia absoluta dos EUA começou a declinar na década de 1970 com a guerra do Vietnã, o fim do padrão dólar e o primeiro choque do petróleo. De acordo com Wallerstein, por exemplo, a guerra do Vietnã foi um grande baque para o poderio militar americano e acabou por mostrar a fragilidade do gigante diante dos vietcongs (combatentes do Vietnã do Norte), abrindo um novo precedente no que se refere à dominação dos EUA no campo militar a nível mundial, ou seja, era o início do fim da força militar americana imbatível e uma indicação de uma ruptura mais profunda.

O fim do padrão ouro, uma decisão tomada pelo então presidente americano Richard Nixon em 1971, trouxe mudanças do ponto de vista financeiro, uma vez que a economia americana passou a se abrir de forma ampla ao capital internacional e os americanos passaram por momentos de crises inflacionárias, que para Wallerstein, seriam um forte indício do começo do fim da hegemonia americana, haja vista a 
inabilidade deste país para lidar com as crises financeiras que assolaram a economia mundial a partir de então. Já a crise do petróleo, iniciada quando os países árabes decidiram diminuir a produção do produto para aumentar o preço do combustível, foi mais uma barreira enfrentada pelo hegemon americano. Além do aumento no preço do combustível os produtores do Oriente Médio resolveram embargar a venda do produto para a Europa e os EUA devido ao apoio dado por estes países a Israel durante a guerra do Yom Kippur em 1973 (o dia do perdão em Israel). Essa atitude dos árabes trouxe consequências para os EUA, uma vez que uma fonte energética tão essencial para a manutenção de seu império global foi usada como arma política, pela primeira vez, num esforço para contestar o poderio ianque.

Wallerstein usa tais eventos para justificar o declínio da hegemonia americana no sistema internacional e vai ainda mais longe ao afirmar que não apenas o fim dos EUA como o único hegemon é certo, mas que o sistema internacional que se conhece hoje também está fadado ao fracasso. Para justificar sua afirmação, Wallerstein usa a teoria sistêmica, a qual prega a ideia de que o sistema internacional atual é fruto de interações e contradições de longos períodos históricos. Esta linha teórica afirma que o atual sistema interestatal foi iniciado na Europa, no que se chamou de longo século XVI, baseando-se na ideia braudeliana dos longos períodos históricos.

Porém, Fiori (2008) destaca que nenhum dos teóricos da teoria sistêmica explica claramente como as crises dos anos de 1970 acabaram contradizendo aquilo que eles defendiam (o começo do declínio americano), haja vista que ditas crises acabaram fortalecendo os EUA ainda mais no cenário político internacional. Apontando as incoerências das teorias de teóricos sistêmicos como Wallerstein e Arrighi, por exemplo, Fiori afirma que a derrota na guerra do Vietnã serviu de lição para os americanos no que concerne a uma virada estratégica, não só do ponto de vista político, como militar, uma vez que o país passou por uma revolução tecnológica que desembocou na vitória americana na primeira Guerra do Golfo em 1991.

Quanto à desregulação econômica, o autor contradiz os teóricos marxistas ao afirmar que esse processo só contribuiu para fortalecer os americanos no cenário mundial, uma vez que o capital financeiro americano triunfou a partir dos anos de 1990 . Nas palavras de Fiori (p.18), o que se viu após as crises dos anos de 1970, "não foi o 
'declínio americano', mas uma mudança estrutural do sistema mundial e um aumento exponencial do poder dos Estados Unidos". Ele prefere defender uma linha teórica que enxerga as crises econômicas e as derrotas militares sofridas pelos americanos como um momento de relativo declínio do poderio dos EUA, mas não como sua derrota absoluta, explicitando uma visão baseada na teoria da tese da explosão expansiva.

Essa teoria prega que os estados criam o caos e a ordem por meio da competitividade entre si e com isso deram origem às várias expansões ao longo da história. Ao invés de descartar os EUA como um poder hegemônico que ainda estará por aqui no futuro, como defendem os teóricos do colapso do império americano, Fiori (2008) afirma que os Estados Unidos terão um papel decisivo na reorganização do sistema por meio da explosão expansiva em curso. Ele diz que o atual sistema é resultado da crise dos anos de 1970, a qual gerou uma nova explosão expansiva do sistema mundial, culminando nas contradições deste início de século. Esta crise estaria ligada à ascensão de novos estados soberanos no cenário mundial, ao crescimento econômico de estados asiáticos, especialmente a China, e à estratégia expansionista imperial americana, mais visível após os atentados de 11 de setembro.

\section{Hegemonia coerciva}

O início do século XXI trouxe uma mudança de paradigma para a política externa americana após os atentados de 11 de setembro de 2001. Esse evento contribuiu para o questionamento em torno das vulnerabilidades americanas e de sua capacidade para manter-se como poder hegemônico, além de inaugurar, da pior forma possível, a nova abordagem dos EUA em relação à política externa a ser praticada no início do século XXI. Tendo a "guerra ao terror" como justificativa, o presidente George Bush defendeu uma política bélica e intervencionista sem precedentes na história americana através do recrudescimento de seu militarismo.

De acordo com Sami Amin (2004), a política americana é agressiva e imperialista e os EUA se utilizam de sua capacidade militar para impor sua hegemonia no cenário internacional Mas para o autor, ao contrário do que afirmam outros teóricos, a hegemonia americana é débil, só podendo ser considerada total na esfera militar. Amin 
(p.82) diz que a economia americana, por exemplo, é parasitária, dependendo dos recursos do Japão, da União Europeia e dos países pobres do sul para sobreviver. "Praticamente em todos os segmentos do sistema produtivo [americano], inclusive dos bens de alta tecnologia, o superávit cedeu lugar a um déficit”, explica. Para Amin, os Estados Unidos só são bem-sucedidos porque detêm vantagens decisivas sobre seus competidores europeus e o Japão no campo econômico.

Como o setor militar americano não sofre das debilidades de outras esferas, como a econômica, por exemplo, é exatamente pela via bélica que os norte-americanos conduzirão seu projeto hegemônico. Essa política agressiva dos EUA, na visão de Amin, faz parte de um programa perpetrado pela sociedade americana e pelo governo de Washington com o objetivo de dominar o mundo. As estratégias americanas na defesa de seus ideais expansionistas, indicam, segundo Amin (2004), que os EUA jamais abandonaram a concepção de serem eles a grande potência planetária desde 1945. Os esforços continuados para agregar áreas de influência no mundo inteiro têm sido uma constante na vida política americana e isso tem ficado ainda mais claro após o 11 de setembro, haja vista a política ainda mais expansionista e belicista desenvolvida por Washington. Essa visão é partilhada por Michael Mann (2006), que afirma ser a esfera militar a única que permite aos EUA ainda deter a primazia política no mundo; dada a fragilidade da economia americana que já está presente há algum tempo, Mann acredita que o militarismo exacerbado dos EUA acabará por destruí-lo.

Segundo Samir Amin (2004), esse militarismo exacerbado dos EUA teve implicações especialmente desastrosas para o Oriente Médio, região, segundo o autor, considerada de extrema importância estratégica para os americanos. De acordo com Amin, é neste local que os EUA demonstram, ao longo do pós-guerra e mais fortemente, após 2001, sua força hegemônica, tendo inclusive impedido que qualquer outra potência tenha significante influência na região desde 1945, que o digam os russos, expulsos pelos mujahedins, guerreiros afegãos que lutaram contra a invasão soviética, apoiados pelos americanos no fim dos anos de 1980. Com a justificativa da guerra ao terror, os EUA ignoraram o Direito Internacional e invadiram o Iraque em 2003, sem a aprovação das Nações Unidas, numa clara manifestação de como o país se vê no cenário internacional, ou seja, sem nenhum poder que lhe rivalize, nem mesmo a ONU. 
Esse tipo de ação causou aos EUA uma perda de prestígio e o país já não vinha sendo bem-visto pelos olhos da comunidade internacional desde os anos de 1990, haja vista as constantes intervenções militares perpetradas ao redor do globo. Segundo Fiori (2008), isso mostra que existem limitações na prática do poderio americano no mundo, uma vez que dominar o planeta de forma vertical é extremamente oneroso, mas isso não significa dizer absolutamente que o império americano esteja no princípio do fim, como afirma Fiori (p.40) "porque apesar dos seus revezes recentes e de suas dificuldades econômicas, os Estados Unidos seguem sendo o único player global". Significa apenas que os EUA precisam rever suas estratégias e trabalhar com outras potências, como a Alemanha, a Rússia e a China, pois estes países constituem fortes atores regionais, capazes de aliarem-se ao EUA numa hegemonia compartilhada, porém com a liderança americana.

\section{Considerações finais}

Apesar de visões contrárias, é possível entender que os EUA ainda são a única potência mundial na acepção mais estrita do termo, uma vez que os americanos ainda detêm o poderio militar e econômico do globo, porém não sem ter sofrido revezes, o último deles, a crise econômica que ainda faz estragos. Mesmo com uma política de cunho expansionista e bélico em relação ao mundo, é fato, como afirmam Fiori e Amin, que os EUA estão passando por um momento delicado em relação à sua existência enquanto potência, uma vez que por causa de erros cometidos nas esferas político-militar e econômica e pela conjuntura do pós-Guerra Fria, os EUA precisam rever a forma como vão operar sua presença no cenário internacional a partir de agora.

Fiori (2008) cita um claro exemplo de como as estratégias da política externa americana resultaram em desastres políticos que devem levar os EUA a repensarem suas ações neste início de século. Ele cita o caso da invasão iraquiana em 2003, onde os sunitas, liderados por Saddam Hussein foram derrotados e o governo do país foi entregue aos xiitas, o que acabou por fortalecer o Irã e o nacionalismo religioso. 0 Iraque acabou virando uma base para o extremismo xiita apoiado pelo Irã e por grupos terroristas como Hamas e Hezbollah. A partir desse momento, os EUA ganharam mais um inimigo no Oriente Médio, o extremismo xiita apoiado por governos locais não simpáticos à presença americana na 
região. Some-se a isso, a crescente presença russa e chinesa na região, as quais têm se aproveitado do status de árbitro perdido pelos EUA nesta área tão importante estrategicamente para as grandes potências. Além disso, há ainda o distanciamento provável da UE em relação aos EUA e o protagonismo de países da América Latina, especialmente o Brasil, como possíveis obstáculos para a hegemonia americana.

Por estes e outros motivos, os americanos devem rever sua estratégia política se desejarem permanecer no posto de único hegemeon neste século. Mesmo com o aumento da influência de países como Rússia, China, Índia, e da União Europeia no cenário internacional, o poder hegemônico dos EUA não está ameaçado, pelo menos até o momento. Porém, como já foi mencionado, não se pode negar um declínio parcial dessa hegemonia, o qual é fruto da conjuntura sistêmica do pós-Guerra Fria e de estratégias malogradas ao longo dos últimos anos pelos EUA.

Do ponto de vista econômico é possível haver uma colaboração entre os EUA e a China; neste século um duelo final entre as duas superpotências está longe de acontecer, como saliente Fiori (2008). Parece que os americanos continuarão a dar as cartas no presente século, nem que seja como a única grande potência militar.

\section{Referências Bibliográficas}

AMIN, Samir. Política do Imperialismo Contemporâneo. In: Atilio Borón (Org.), Nova Hegemonia Mundial Buenos Aires, p. 73: 110, 2004.

FIORI, José Luis. O sistema interestatal capitalista no início do século XXI. In: Fiori, J.L; Medeiros, Carlos; Serrano, F.(orgs.) O Mito do Colapso do Poder Americano. Rio de janeiro: Record, p.11:70, 2008.

KEOHANE, Robert O.; KATZENSTEIN, Peter J.; The Politics of Anti-Americanism. 2005. disponível em <http://www.princeton.edu/ rkeohane/publications/AntiAmerInWPIntro.pdf > acesso em 30/07/2013. 
KINDLEBERGER, Charles. The World in Depression, 1929-39. Berkeley: University of California Press, 1973, pp. 291-308. Disponível em: <https://www.mtholyoke.edu/acad/intrel/depress.htm > acesso em 10/10/2013.

MANN, Michael. 0 império da Incoerência. Rio de Janeiro, Record, 2006.

SNIDAL, Duncan. The Limits of hegemonic stability theory. In: International Organization, vol 39, $\mathrm{n}^{\circ} 04$ (1985), p. 579-614. Disponível em: <http://www.rochelleterman.com/ir/sites/default/files/Snidal\%201985.pdf acesso em 10/10/2013. 